\title{
Assessing the Potential to Change Stakeholders Knowledge and Practices on Fertilizer Recommendations in Africa
}

\author{
Harrison Rware ${ }^{1}$, Lydia Wairegi ${ }^{1}$, George Oduor ${ }^{1}$, Martin Macharia', Dannie Romney ${ }^{1}$, \\ Bitrus Dawi Tarfa ${ }^{3}$, Ricardo de Maria', George Ley5, Francis Tetteh ${ }^{6}$, Wilson Makumba ${ }^{7}$, \\ Mohamed Dicko", Maman Nouri', Nabahungu N. Leon' ${ }^{10}$, Brian Gondwe ${ }^{11}$, Kayuki Kaizzi ${ }^{12}$, \\ Demissie Negash $^{13}$, Catherine Kibunja ${ }^{14}$, Abdillahi Alawy' ${ }^{1}$ Charles Wartmannn, \\ Emmanuel Rutsimba ${ }^{2}$
}

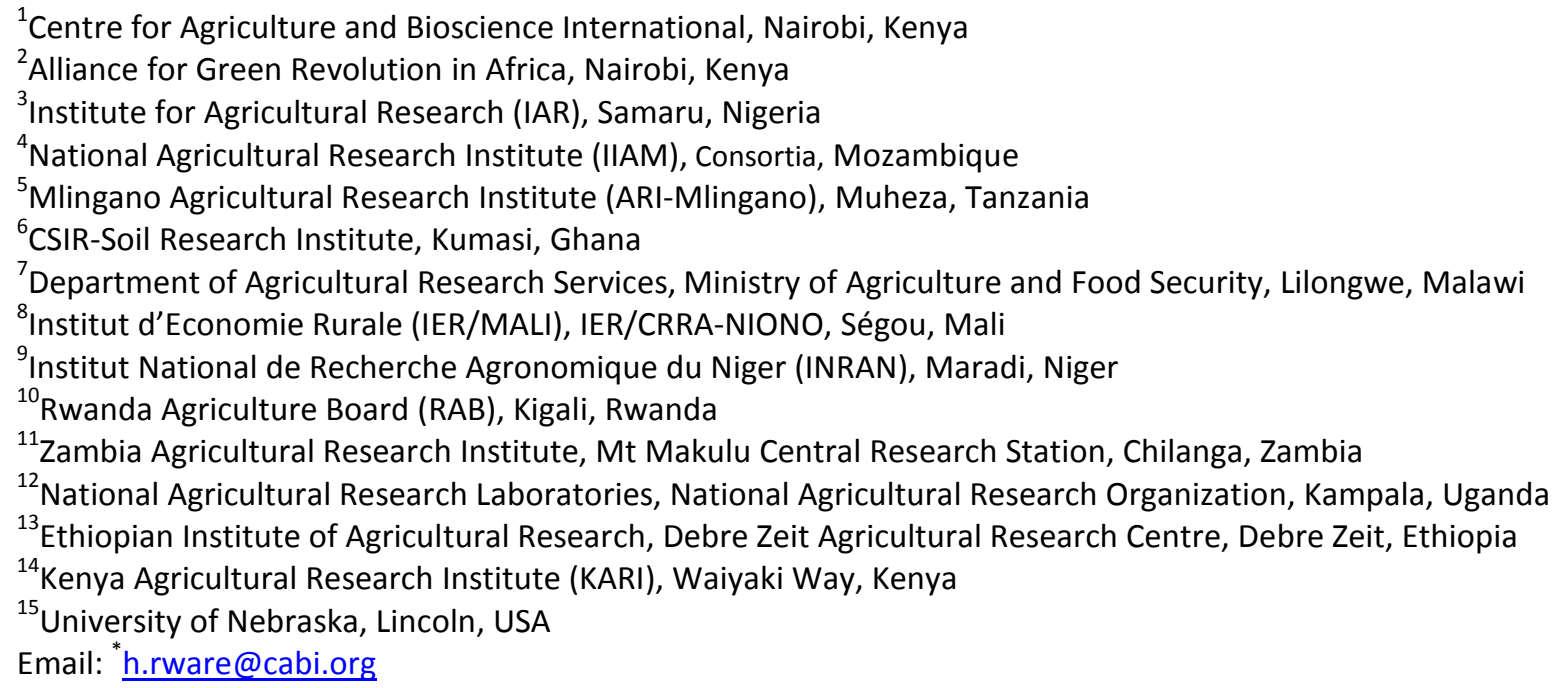

Received 10 October 2014; revised 27 October 2014; accepted 10 November 2014

Academic Editor: Susan Njeri Wamitu, Kenya Methodist University, Nyeri Campus, Kenya

Copyright (C) 2014 by authors and Scientific Research Publishing Inc.

This work is licensed under the Creative Commons Attribution International License (CC BY). http://creativecommons.org/licenses/by/4.0/

c) (i) Open Access

\section{Abstract}

Africa's fertilizer use averages only 8 kg per hectare per year. Available fertilizer recommendations in Africa are high, and vary between countries. The recommendations are generally out dated, and/or "blanket" recommendations that are not site, or crop specific. Recommendation de*Corresponding author. 
veloped for one crop is often used for another and possibly unrelated crop. CABI and AGRA designed a project whose goal is "to help improve the capacity of National Research Institutions in developing fertilizer recommendations for efficient and profitable fertilizer use in 13 sub-Saharan African countries within the framework of ISFM practices under smallholder farming by the end of March 2016". Baseline survey conducted in May 2014 targeted scientists, policy makers, extension workers, agro-dealers, fertilizer companies and farmers/farmer organization. Snowballing and convenience sampling techniques were used to get the sample and emails were used to reach the respondents. A total of 416 respondents were targeted but only 219 responded from 12 countries. Out of the 219, 148 were extension workers and researchers. About half $(51 \%)$ of the scientists are aware of fertilizer optimization tool, and a lesser proportion have used the tool across all countries $(31 \%)$. Fewer extension workers $(31 \%)$ were aware of the fertilizer optimization tool and none reported to have used the tool. On average about $5 \%$ of the study participants reported that other stakeholders were involved in the development of fertilizer recommendations including farmers, farmer organizations, policy makers, researchers, extension workers, agro dealers, fertilizer companies and donor organizations. Stakeholder involvement was highest in Nigeria at $15 \%$, followed by Ethiopia (13\%) and Malawi $(10 \%)$ but most of the countries reported $<5 \%$. There is a general understanding that development of fertilizer recommendations is a multistakeholder initiative and therefore need for involving many stakeholders in the development of fertilizer recommendations across Africa that will fosters greater ownership and sustainability.

\section{Keywords}

Fertilizer Recommendations, Stakeholders, Knowledge, Practices

\section{Introduction}

Africa's fertilizer use averages only $8 \mathrm{~kg}$ per hectare per year. That is, only $10 \%$ of the world's average and to address the Africa's fertilizer crisis, concerted and urgent and bold actions are required. African leaders convened in Abujain 2006, to show their strong and unanimous commitment to achieve the African Green Revolution by taking immediate actions to solve Africa's fertilizer crisis [1]. In many countries the use of fertilizer is very low, with an average for sub-Saharan Africa of $8 \mathrm{~kg} \cdot \mathrm{ha}^{-1} \cdot \mathrm{yr}^{-1}$ [2]. The application of fertilizer on degraded soils and without following recommendations has resulted in low crop yields with most countries having maize yields of less than $1 \mathrm{t} \cdot \mathrm{ha}^{-1}$ as compared to potential yields of up to $8.6 \mathrm{t} \cdot \mathrm{ha}^{-1}$ under ideal conditions. Therefore, the use of fertiliser, in combination with other soil management measures, is necessary to combat the poor soil fertility so as to increase yields [1] [2].

\subsection{Status of Fertilizer Recommendations}

Researchers have shown that the observed rates of fertilizer applications are low and available recommendations remain high [3]-[5]. Further they have pointed out that these recommendations vary between countries but are generally out dated, and/or "blanket" recommendations that are not site, or crop specific. A recommendation developed for one crop is often used for another possibly unrelated crop in the absence of any other information e.g. previously a recommendation for cotton was also used for cereal crops in Burkina Faso. Recommendations for a crop also do not take account of agro-ecological conditions or the soil type in which the crop is being grown: for instance in Zambia a standard recommendation of $200 \mathrm{~kg} \cdot \mathrm{ha}^{-1}$ "D" compound as a basal dressing was recommended with a $200 \mathrm{~kg} \cdot \mathrm{ha}^{-1}$ top dressing, across all soil types, climatic zones and crops. Lastly, there is no information on how to adjust fertilizer use for different cropping systems (e.g. intercropping), crop rotations, and other soil fertility management practices such as use of manure.

In addition, fertilizer recommendations have typically been developed with the intent of maximizing yield or profit per hectare. The latter is generally appropriate with well-financed farming where farmers have the financial ability to apply fertilizer across all of their crop land to maximize net returns per hectare; this is generally their most profitable option. Smallholder farmers use little fertilizer due to inefficiencies across the fertilizer 
value chain meaning that fertilizer is not available in outlets close to the farmer at the time when they are needed, procurement cost, and the high opportunity cost (money spent on fertilizer is not available for other needs). Thus, smallholders typically cannot apply fertilizer to all of their cropland if they apply at rates to maximize net returns per hectare. Often, they can apply fertilizer on only a small part of their farm, and therefore need to make choices that maximize the benefit-to-cost ratio; this implies that applications should be based on the crop-nutrient rate combinations that give the greatest net returns for their investment capacity [4]. However, existing recommendations do not allow farmers to maximize net returns on their investment. In addition a lack of information about correct application rates, timings, and the use of the correct products for different crops compounds the problems associated with blanket fertilizer recommendations [1].

It is out of this need that CABI together with AGRA developed a project whose goal is "to help improve the capacity of National Research Institutions in developing fertiliser recommendations for efficient and profitable Fertiliser use in 13 sub-Saharan African countries within the framework of ISFM practices under smallholder farming by the end of March 2016".

Prior to the implementation of the project, a study was conducted to find the following at stakeholder's levels.

1) The level of awareness of the fertilizer optimisation tool among the scientists and extension workers;

2) The level to which different stakeholders are involved in the development of fertiliser recommendation;

3) The level at which fertilizer recommendations are specific to crops, AEZs and farmers profitability.

\subsection{Methodology}

A baseline study was conducted in 12 countries namely, Ethiopia, Ghana, Kenya, Malawi, Mali, Niger, Nigeria, Mozambique, Rwanda, Tanzania, Uganda and Zambia where Optimization Fertilizer Recommendations for Africa (OFRA) project is being implemented. Initial questionnaire were developed and shared with the Principal Investigators (PIs) of each of the participating countries at the OFRA inception workshop in November 2013 where their inputs were solicited. The questionnaires were structured for different categories of study participants who included researchers (soil scientists and agronomists) from local universities, international NGOs research institutions and National Agricultural Research Systems (NARS), extension workers, policy makers' representatives, farmers/farmer groups, agro dealers and fertilizer companies.

Snowballing sampling techniques were used to generate the sample number from the six (6) categories of study participants for this study [6]. The strategy has before been used to overcome the problems associated with understanding and sampling concealed populations such as the deviant and the socially isolated [7]. This was informed by the fact that the information sought for the baseline was unique and targeted and therefore the number of study participants from each category was informed, to a large extent, by the importance of the category in the generation of fertilizer recommendations. Snowballing sampling involved asking a few people known to be involved in fertilizer research in various institutions for names and contacts of similar individuals in their institutions or other similar institutions. In each of the 13 countries a sample for each of the six categories was generated and information gathering conducted using electronic emails transfers.

The PIs from each of the countries were asked to provide a list of study participants in each of the categories listed above using their country networks. Further, with the support from the AGRA-funded National Soil Health Consortia's in the countries, names of more contacts for scientists were added to the list of study participants and lists of the policy makers and fertilizer companies were generated. Questionnaires were then administered via emails to each category of selected study participants and the country PIs were copied in for follow-up. Where flow of responses was slow, follow-up was made on phone to ensure there were enough responses for each category.

\section{Data Analysis}

Data was entered in a Microsoft Access database and transferred to a statistical package (SPSS) for analysis. Results were disaggregated by countries and respondent categories. The proportions/percentages were based on number of responses to specific questions.

\section{Results and Discussion}

Although definite numbers of study participants in each category were targeted (Table 1), the number of actual study participants were below expectations due to challenges faced in the use of emails as a methods of reaching study participants or because the PIs, who were expected to support the baseline process, were in the field estab- 
Table 1. Study participants categories and targeted numbers.

\begin{tabular}{ccc}
\hline Respondent category & Number of targeted study participants per country & Targeted total in 13 countries \\
\hline 1) Scientists & 10 & 130 \\
2) Extension workers & 10 & 130 \\
3) Policy maker's & 3 & 39 \\
4) Farmers/farmer's groups & 3 & 39 \\
5) Agro dealers & 3 & 39 \\
6) Fertiliser companies & 3 & 416 \\
Total & & 39 \\
\hline
\end{tabular}

Source: [12].

lishing or managing trials as it was during the rainy season. However, the use of different methodologies mitigated against the problem. As expected, most responses were from scientists who are involved in the development of the fertilizer recommendations under OFRA, followed by the extension workers, policy makers, and agro-dealers. Overall, Ethiopia had the largest number of scientist responding followed by Kenya. Burkina Faso had no study participants (Table 2). Some countries have fewer fertilizer companies and others have no fertilizer companies such as Niger hence the low responses on this category.

\section{Researchers and Extension Staff Using Fertiliser Optimisation Tool}

Scientists and extension workers are key stakeholder in the development and dissemination of the fertiliser optimisation tool (FOT). It is due to the critical role they play that they were targeted to answer the questions on knowledge and utilization of the fertiliser optimisation tool. In response, despite the fact that majority scientists reported to know the FOT (50.8\%), a lesser proportion reported to have used the tool across countries. On the other hand, the scenario was the same for the extension workers, where $31.3 \%$ reported to know a FOT but none reported to have used a FOT. Some of the challenges in using the tool, lack training (62\%) in the field while others $18 \%$ reported to lack computer, lack of software that is validated to the AEZs while a small percentage (7\%) reported that the tool is too laborious, the tool requires too much data for operation (Table 3).

\subsection{Fertilizer Recommendations}

Fertilizer recommendations are critical to ensuring that there balance between farmers' need for location and farm-specific recommendations. It is against this backdrop that we asked the farmers and policy makers to say if farmers used fertilizers where $14.8 \%$ reported use of fertilizers. In the OFRA inception workshop the principle investigators from project countries stated fertilizer recommendations for various crops. However, of all the crops, maize recommendations were mentioned in 12 countries. Out of 12 maize recommendations, 6 (50\%) of the fertiliser recommendations do not follow Agro ecological zones (AEZ). Although Ghana had the highest number of crop systems specific fertilizer recommendation out of 6 crops (Maize, Beans, Rice, Wheat, Millet, and Cassava) none were shown to target specific AEZs. No fertilizer recommendations were reported to follow AEZ in Ethiopia, Mali and Mozambique. Interviews with key informants in Tanzania during the ISFM stakeholders Forum in June 2014 confirmed that there are 4 cropping system focused fertilizer recommendations in Tanzania, but none of the crop fertilizer recommendations follow AEZ [8] (Table 4).

During the baseline study, when scientist, extension workers, agro dealers and farmer organizations were asked to state whether the fertilizer used followed recommendations. There was none who reported that fertilizer recommendations were followed in Kenya, Mozambique, Mali, Malawi, Burkina Faso, and Zambia. On average, about $11 \%$ from 7 countries out of 13 countries reported to following fertilizer recommendations (Table 5). The failure to follow the recommendations was attributed to the financial constraints commonly among the small holder scale farmers that limit fertilizer use as they strive to maximize net returns on their investments. In Uganda, the fertilizer recommendations that were developed under 2009 SHP 001 considered only inorganic fertilizers which are just one component of the ISFM strategy [9]. In Rwanda, the existing fertilizer recommendations are blanket in nature and do not incorporate the integrated soil fertility management (ISFM). Thus these fertilizer recommendations are uneconomical and do not respond to the sustainability of the environment to produce sufficient food for Rwandan farmer community [10]. Zambia is implementing research under the fund- 
Table 2. Characteristics of respondents.

\begin{tabular}{|c|c|c|c|c|c|c|c|}
\hline \multirow[b]{2}{*}{ Country } & \multicolumn{7}{|c|}{ Category of study participant } \\
\hline & Scientists & Extension workers & Policy makers & Farmer organization & Agro-dealers & Fertilizer companies & Total \\
\hline Bukina Faso & 0 & 0 & 0 & 0 & 0 & 0 & 0 \\
\hline Ethiopia & 12 & 4 & 1 & 0 & 1 & 1 & 19 \\
\hline Ghana & 5 & 8 & 2 & 2 & 2 & 3 & 23 \\
\hline Kenya & 11 & 10 & 2 & 3 & 4 & 2 & 31 \\
\hline Malawi & 9 & 3 & 0 & 1 & 1 & 0 & 14 \\
\hline Mali & 5 & 5 & 0 & 0 & 0 & 0 & 10 \\
\hline Mozambique & 4 & 3 & 1 & 0 & 1 & 1 & 10 \\
\hline Niger & 10 & 3 & 2 & 1 & 1 & 0 & 17 \\
\hline Nigeria & 10 & 1 & 3 & 1 & 0 & 1 & 16 \\
\hline Rwanda & 9 & 5 & 1 & 1 & 1 & 2 & 19 \\
\hline Tanzania & 8 & 5 & 2 & 1 & 1 & 2 & 19 \\
\hline Uganda & 4 & 10 & 1 & 9 & 1 & 7 & 32 \\
\hline Zambia & 4 & 2 & 2 & 0 & 0 & 1 & 9 \\
\hline $\begin{array}{l}\text { Total study } \\
\text { participants }\end{array}$ & 91 & 57 & 16 & 19 & 12 & 18 & 219 \\
\hline Number targeted & 130 & 130 & 39 & 39 & 39 & 39 & 416 \\
\hline
\end{tabular}

Source: [12].

Table 3. Proportion of soil researchers and extension staff aware and using fertiliser optimisation tools by country.

\begin{tabular}{ccccc}
\hline & \multicolumn{2}{c}{ Scientists } & \multicolumn{2}{c}{ Extension workers } \\
\cline { 2 - 5 } Country & $\begin{array}{c}\text { Know fertiliser } \\
\text { optimisation tool }\end{array}$ & $\begin{array}{c}\text { Used fertiliser } \\
\text { optimisation tool }\end{array}$ & $\begin{array}{c}\text { Know fertiliser } \\
\text { optimisation tool }\end{array}$ & $\begin{array}{c}\text { Used fertiliser } \\
\text { optimisation tool } \\
\%\end{array}$ \\
\hline Ethiopia & $23(7)$ & $\%$ & $16(3)$ & $0(0)$ \\
Burkina Faso & $0(0)$ & $22(4)$ & $0(0)$ & $0(0)$ \\
Ghana & $19(6)$ & $0(0)$ & $16(3)$ & $0(0)$ \\
Kenya & $23(7)$ & $0(0)$ & $0(0)$ & $0(0)$ \\
Malawi & $10(3)$ & $6(1)$ & $16(3)$ & $0(0)$ \\
Mali & $10(3)$ & $0(0)$ & $0(0)$ & $0(0)$ \\
Mozambique & $6(2)$ & $0(0)$ & $0(0)$ & $0(0)$ \\
Niger & $10(3)$ & $6(1)$ & $16(3)$ & $0(0)$ \\
Nigeria & $16(5)$ & $6(1)$ & $0(0)$ & $0(0)$ \\
Rwanda & $6(2)$ & $17(3)$ & $0(0)$ & $0(0)$ \\
Tanzania & $19(6)$ & $6(1)$ & $16(3)$ & $0(0)$ \\
Uganda & $14(4)$ & $6(1)$ & $16(3)$ & $0(0)$ \\
Zambia & $6(2)$ & $11(2)$ & $0(0)$ & 0 \\
\hline
\end{tabular}

${ }^{* *} \mathrm{~N}$ in parenthesis. Source: [12].

ing of AGRA SHP to develop appropriate fertilizer recommendation rates for maize in 4 major production/ AEZs in the country [11].

Fertilizer development in most of the Sub-Saharan countries do not take into consideration Agro Ecological Zones (AEZ) differences of the location of the agricultural farms and thus the fertilizer recommendations made are general with little or no consideration to geographical differences. For instance, a recommendation developed for one crop is often used for another possibly unrelated crop in the absence of any other information. Recommendations for a crop also do not take account of agro-ecological conditions or the soil type in which the crop is being grown (OFRA Proposal, 2013). Farmer organisation, agro dealers and fertilizer companies were asked to say if the fertilizers recommendation that exist targets specific crops, agro-ecological zones (AEZs), 
Table 4. Fertiliser recommendations by country.

\begin{tabular}{|c|c|c|c|c|}
\hline Country & $\begin{array}{l}\text { Crops with fertilizer } \\
\text { recommendations }\end{array}$ & $\begin{array}{l}\text { Number fertiliser } \\
\text { recommendations that are } \\
\text { crop specific }\end{array}$ & $\begin{array}{l}\text { Number of fertilizer } \\
\text { recommendations that are } \\
\text { AEZ specific }\end{array}$ & $\begin{array}{l}\text { Proportion of fertiliser } \\
\text { recommendations that are } \\
\text { AEZ specific (\%) }\end{array}$ \\
\hline Burkina Faso & Maize, Rice, Sorghum & 4 & 0 & 0 \\
\hline Ethiopia & $\begin{array}{l}\text { Maize, Sorghum, Soya Bean, } \\
\text { Wheat, Teff }\end{array}$ & 5 & 0 & 0 \\
\hline Ghana & $\begin{array}{l}\text { Maize, Beans, Rice, Wheat, } \\
\text { Millet, Cassava }\end{array}$ & 6 & 0 & 0 \\
\hline Kenya & $\begin{array}{c}\text { Maize, Sorghum, Pigeon Pea, } \\
\text { Cow Pea, Rice, Beans, Soya } \\
\text { Beans, Wheat }\end{array}$ & 9 & 1 & 11 \\
\hline Malawi & Maize, Soya Bean & 2 & 0 & 0 \\
\hline Mali & Maize, Millet & 2 & 0 & 0 \\
\hline Mozambique & $\begin{array}{l}\text { Millet, Soya Bean, Sorghum, } \\
\text { Rice, Maize }\end{array}$ & 5 & 0 & 0 \\
\hline Niger & $\begin{array}{l}\text { Maize, Rice, Soya Bean, } \\
\text { Sorghum, Millet }\end{array}$ & 5 & 1 & 20 \\
\hline Nigeria & $\begin{array}{l}\text { Maize, Rice, Soya Bean, } \\
\text { Sorghum }\end{array}$ & 4 & 1 & 25 \\
\hline Rwanda & Maize, Rice, Soya Bean & 3 & 1 & 33 \\
\hline Tanzania & Maize and Rice & 4 & 0 & 0 \\
\hline Uganda & $\begin{array}{l}\text { Maize, Beans, Soya Beans, } \\
\text { Cassava, Ground Nuts, Cotton }\end{array}$ & 4 & 0 & 0 \\
\hline Zambia & Maize, Soya Beans & 2 & 0 & 0 \\
\hline
\end{tabular}

Source: [8].

Table 5. Proportion of respondents following fertilizer recommendations by country.

\begin{tabular}{ccc}
\hline Country & No & Yes \\
\hline Kenya & $\%$ & 0 \\
Mozambique & 10 & 0 \\
Mali & 20 & 0 \\
Malawi & 0 & 0 \\
Burkina Faso & 20 & 0 \\
Uganda & 0 & 10 \\
Tanzania & 20 & 10 \\
Rwanda & 30 & 10 \\
Zambia & 20 & 20 \\
Ghana & 30 & 10 \\
Ethiopia & 10 & 10 \\
Niger & 20 & 10 \\
\hline
\end{tabular}

Source: [12].

accounts for farmer profitability and whether it is adjusted for use by farmers. Majority (18.4\%) of the respondents reported that the fertilizer recommendations accounted for farmers' profitability especially by increasing the yields. $17.2 \%$ the recommendations targeted specific crops where majority of the targeted reported that the targeted crop is maize. Only 5.7\% reported that the fertilizer recommendations targets AEZs (Figure 1).

Disaggregating the results by country, on average only $1(10 \%)$ respondents per country reported that the fertilizer recommendations targets AEZ and is adjusted for use by either reducing the quantities recommended of mixing fertilizer brands. On the other hand, on average, 2 (20\%) respondents per county reported that the recommendations account for farmer's profitability (Figure 2). 


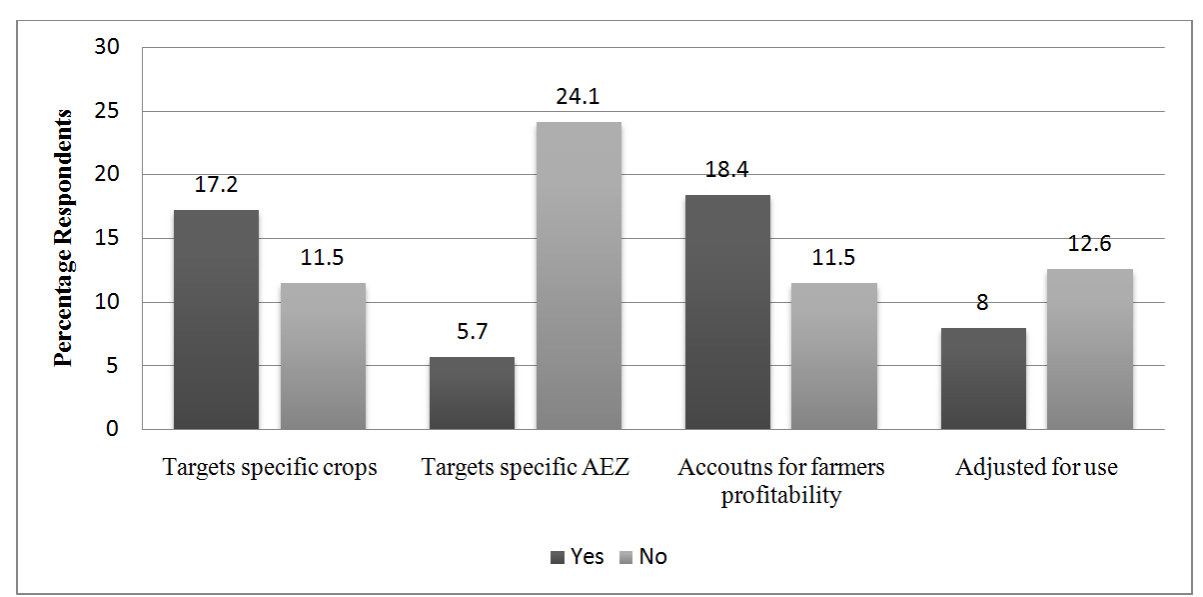

Figure 1. Proportion of respondents reporting on fertilizer recommendations.

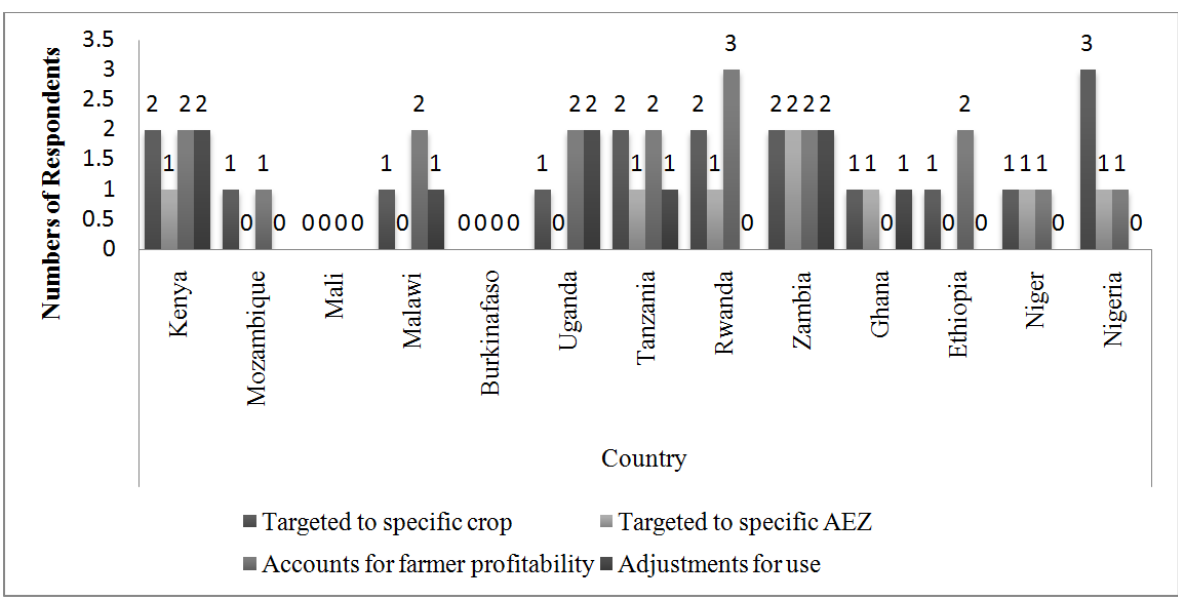

Figure 2. Targeted fertilizer recommendations by country.

\subsection{Stakeholders Involvement in Developing Fertilizer Recommendations in ISFM Context}

Use of fertiliser, in combination with other soil management measures also referred to as Integrated Soil Fertility Management (ISFM) approach, is necessary in combating poor soil fertility and increase in crop yields profitably [1]. To foster ownership, sustainability and wider application of the fertiliser optimization tool, a wide range of stakeholders ought to be involved in the development of these recommendations. Against this background, we sought to find out whether stakeholders are involved in the development of fertiliser recommendations in the context of ISFM in project countries. On average across all countries, over $60 \%$ study participants reported that stakeholders were involved in the development of fertiliser recommendations. Some of the stakeholders mentioned included, farmers, farmer organizations, policy makers, researchers, extension workers, agro dealers, fertiliser companies and donor organizations in the fertilizer supply and use chain. Disaggregating the data across the countries, different stakeholders in developing fertiliser recommendations were highest in Nigeria at $15 \%$, followed by Ethiopia (13\%) and Malawi (10\%). However, most countries reported $<5 \%$ where different stakeholders were involved in the development of fertilisers recommendations.

\subsection{Conclusions and Recommendations}

In conclusion, there is good knowledge that development of fertilizer recommendations is a multi-stakeholder initiative and awareness of the type of stakeholders who need to be involved. There is also substantial awareness of the fertilizer optimization tools (FoT) among the researchers and extension staff in project countries in Africa 
but use of such tools is limited. In this regard, it is recommended that fertilizer recommendation/guidelines development efforts ought to involve as many stakeholders as possible across Africa to foster greater ownership and sustainability of fertilizer recommendations.

With improved fertilizer recommendations that are cropping system and AEZ specific and that take into consideration ISFM, fertilizer use will be more profitable to resource poor small scale farmers. Further, wider dissemination of the improved recommendations in combination with good seed, good agronomic practices (ISFM) will lead to improved yields, income and livelihoods among the low income farmers.

\section{References}

[1] OFRA Proposal (2013) Enhancing National Agriculture Research Capacities in Developing and Fine-Tuning Fertiliser Recommendations within an Integrated Soil Fertility Management Framework.

[2] Morris, M., Kelly, V.A., Kopicki, R.J. and Byerlee, D. (2007) Fertilizer Use in African Agriculture. The World Bank, Washington DC. http://dx.doi.org/10.1596/978-0-8213-6880-0

[3] Foster, H.L. (1976) Soil Fertility in Uganda. Ph.D. Thesis, University of Newcastle on the Tyne.

[4] Kaizzi, C.K., Byalebeka, J., Semalulu, O., Alou, I., Zimwanguyizza, W., Nansamba, A., Odama, E. and Wortmann, C.S. (2012) Upland Rice Response to Fertilizer in Uganda. J. Nutr. Cycl. Agro. Ecosystem.

[5] Donovan, C., Damaseke, M., Govereh, J. and Simumba, D. (2002) Framework and Initial Analyses of Fertilizer Profitability in Maize and Cotton in Zambia. Food Security Research Project. MSU, Zambia.

[6] Babbie, E. (2001) The Practice of Social Research. 9th Edition, Wadsworth Thomson, Belmont.

[7] Lewis-Beck, M.S., Bryman, A. and Liao, T.F. (2004) The SAGE Encyclopedia of Social Science Research Methods.

[8] (2013) OFRA Inception Report.

[9] Kayuki, K. (2013) Developing and Fine Tuning Fertilizer Recommendations within an Integrated Soil Fertility Management Framework in Uganda.

[10] RAB (2013) Developing and Fine-Tuning Fertilizer Recommendations within an Integrated Soil Fertility Management Framework in Rwanda.

[11] Sakala, G. (2013) Developing and Fine-Tuning Fertilizer Recommendations within an Integrated Soil Fertility Management Framework for Maize in Zambia.

[12] Rware, H., Wairegi, L., Oduor, G., Romney, D., Alawy, A. and Macharia, M. (2014) Optimization of Fertilizer Recommendations for Africa Project. Baseline Study Report.

\section{Acronyms}

AEZ: Agro Ecological Zones

AGRA: Alliance for Green Revolution in Africa

FoT: Fertilizer Optimization Tool

IITA: International Institute for Tropical Agriculture

ISFM: Integrated Soil Fertility management

NARS: National Agricultural Research Systems

NGO: Non-Governmental Organizations

OFRA: Optimization for Fertilizer Recommendations for Africa

PI: Principal Investigator

RAB: Rwanda Agricultural Board

SG: Sub Grantee

SHP: Soil Health Program 
Scientific Research Publishing (SCIRP) is one of the largest Open Access journal publishers. It is currently publishing more than 200 open access, online, peer-reviewed journals covering a wide range of academic disciplines. SCIRP serves the worldwide academic communities and contributes to the progress and application of science with its publication.

Other selected journals from SCIRP are listed as below. Submit your manuscript to us via either submit@scirp.org or Online Submission Portal.
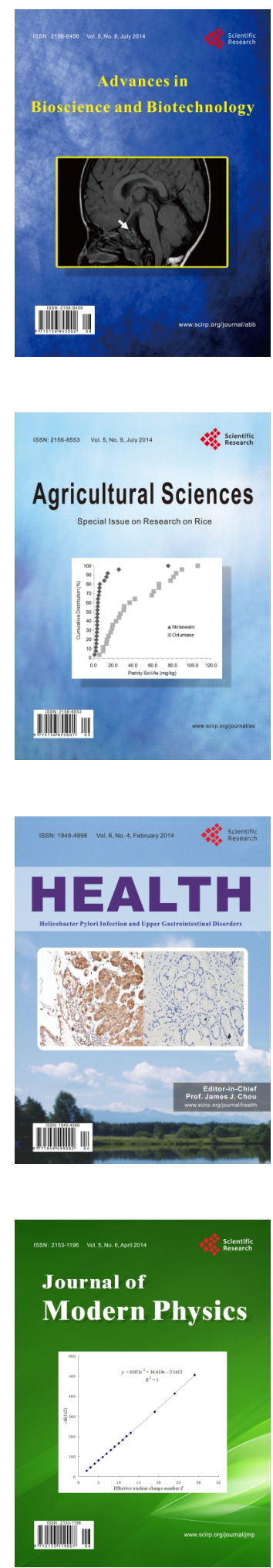
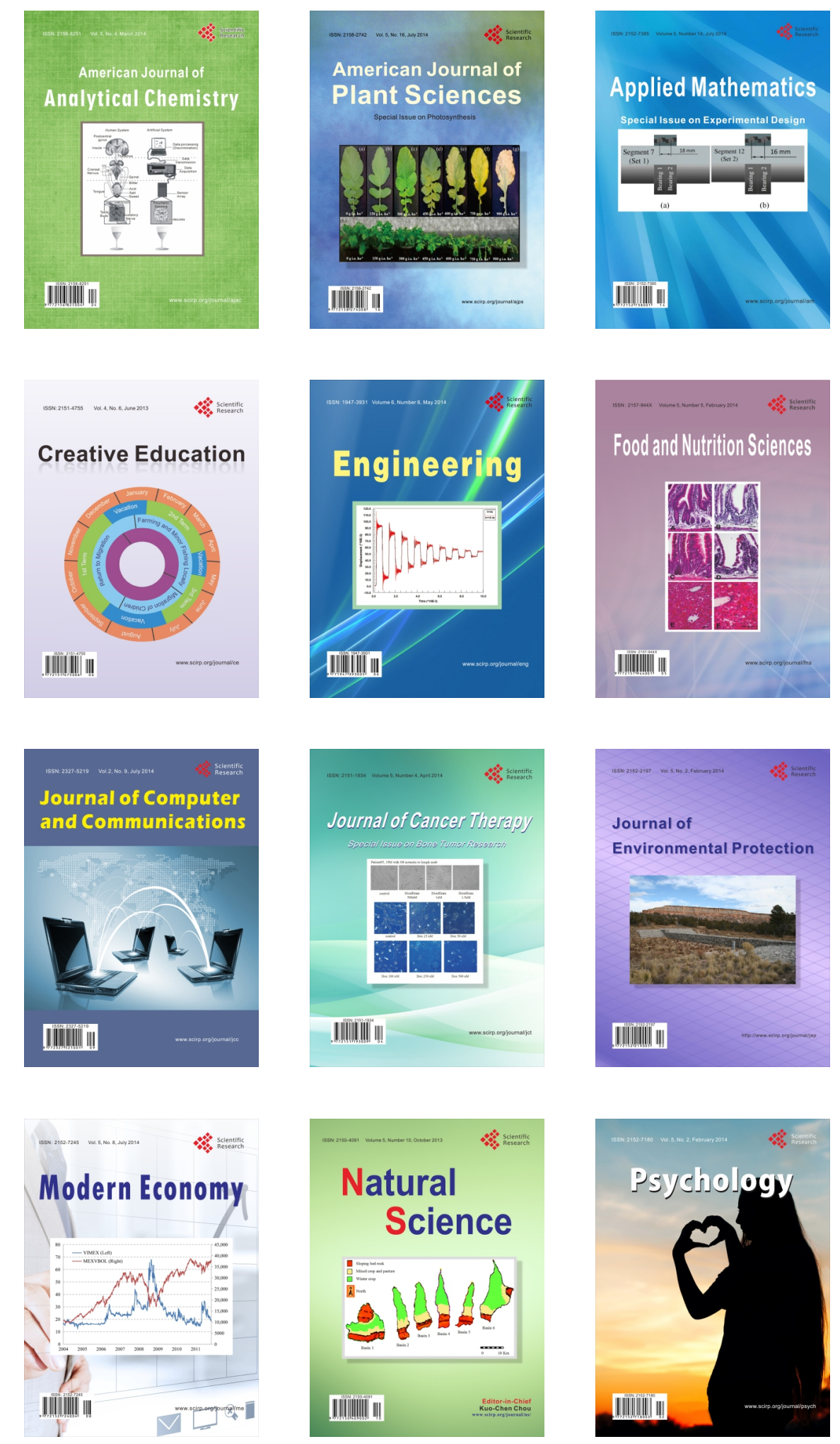